\title{
Fibril-mediated oligomerization of pilin-derived protein nanotubes
}

Anna Petrov ${ }^{1 \dagger}$, Stephanie Lombardo ${ }^{1 \dagger}$ and Gerald F Audette ${ }^{1,2^{*}}$

\begin{abstract}
Background: Self-assembling protein nanotubes (PNTs) are an intriguing alternative to carbon nanotubes for applications in bionanotechnology, in part due to greater inherent biocompatibility. The type IV pilus of the gram negative bacteria Pseudomonas aeruginosa is a protein-based fibre composed of a single subunit, the type IV pilin. Engineered pilin monomers from $P$. aeruginosa strain K122-4 ( $\triangle K 122)$ have been shown to oligomerize into PNTs both in solution and at surfaces. In order to fully exploit PNTs in bionanotechonological settings, an in-depth understanding of their assembly, physical characteristics and robustness, both in solution and when constrained to surfaces, is required.

Results: This study details the effectiveness of multiple initiators of $\triangle K 122$-derived PNT oligomerization and characterize the formation of PNTs in solution. The optimal initiator for the oligomerization of $\triangle K 122$ in solution was observed to be 2-methyl-2,4-pentanediol (MPD). Conversely, larger PEG molecules do not trigger oligomerization. Multi-angle light scattering analysis indicates that the pilin protein exists in a monomer-dimer equilibrium in solution, and that an intermediate species forms within three hours that then coalesces over time into high molecular weight PNTs. Transmission Electron Microscopic analysis was used to observe the formation of oligomerized $\triangle K 122$ fibrils prior to assembly into full-length PNTs.

Conclusions: The oligomerization of $\triangle K 122$ pilin derived PNTs is a fibril mediated process. The optimal trigger for PNT oligomerization in solution is MPD, and the observation that PEGs do not induce oligomerization may enable the oligomerization of pilin-derived PNTs on PEG-functionalized surfaces for implantable bionanodevices.
\end{abstract}

Keywords: Protein nanotubes, Type IV pilin, Type IV pilus, Protein oligomerization

\section{Background}

The development of peptide and protein-based nanotubes as biologically accepted nanosystems have several advantages when compared to their inorganic counterparts such as carbon nanotubes (CNTs), which are significantly more cytotoxic and present biocompatibility issues [1-11]. Peptide and protein based nanotubes can be assembled utilizing both template and nontemplate assembly mechanisms under milder conditions (ambient temperature, physiological $\mathrm{pH}$ ), and provide a readily customizable system via modern protein engineering methods $[12,13]$. In addition, studies have shown that wormlike, filamentous nanoparticles are better than

\footnotetext{
* Correspondence: audette@yorku.ca

${ }^{\dagger}$ Equal contributors

'Department of Chemistry, York University, Toronto, ON M3J1P3, Canada

${ }^{2}$ Centre for Research on Biomolecular Interactions, York University, Toronto, Canada
}

\section{Biomed Central}

(c) 2013 Petrov et al.; licensee BioMed Central Ltd. This is an Open Access article distributed under the terms of the Creative Commons Attribution License (http://creativecommons.org/licenses/by/2.0), which permits unrestricted use, distribution, and reproduction in any medium, provided the original work is properly cited. spherical ones at avoiding immune responses allowing for longer circulation times due to the difficulty of macrophages have adjusting tertiary and/or quaternary structure to engulf such elongated particles [14-16]. Therefore, peptide and protein-based nanotubes will likely have applications as drug-delivery vehicles as their relatively large inner cavity and high surface areas would enable them to transport drug molecules, nucleic acids or antigens to targeted cell surface.

Several recent studies have examined the applicability of nanotubes from peptides [17-20], proteins [21-29], and viruses [30-38]. For instance, the mutation of the pIII and pVII coat proteins of the M13 phage enabled the modified phage to scaffold metal oxides [34,35]. The resultant protein-metal hybrid bionanowires demonstrated significant initial and reversible storage capacity $[35,38]$, suggesting the utility of these nanocomposites for power generating applications. Another system ex- 
amined for protein nanotube (PNT) development is based on the bacterial flagella, where the flagellin protein FliC has been modified to contain a thioredoxin domain [21]. The resultant FliC-thioredoxin chimera was shown to form PNTs on surfaces [22] as well as enable metal nanowire synthesis [39]. These studies highlight the applicability of using bio-inspired PNTs for various applications in nanoelectronics and as biosensors.

In addition to protein-based nanostructures derived from viral coat proteins and flagella, PNTs have been shown to assemble from an engineered form of the type IV pilin $[23,24]$, the monomeric unit of the type IV pilus (T4P) of many gram-negative bacteria including Pseudomonas aeruginosa. Opportunistic infections by $P$. aeruginosa are a significant cause morbidity and mortality in individuals with compromised immune systems (e.g. burn victims [40] and cystic fibrosis patients [41]), with infections being initiated through interaction of T4P with cellular receptors [42-47]. In addition to cellular adherence, T4P are involved in a number of functions including surface adherence [48,49], twitching motility [47,50-54], DNA uptake [55-57], and biofilm formation [47,58-60]. T4P are robust structures assembled and disassembled via a membrane-spanning complex whose architecture is evolutionarily related to a type II secretion system $[47,50,60]$. P. aeruginosa T4P have also been demonstrated to retract at rates of $0.5-1 \mu \mathrm{m} \mathrm{s}^{-1}(\sim 1500$ subunits $\mathrm{s}^{-1}$ ) [51] generating forces exceeding $100 \mathrm{pN}$ [61]. The T4P has an outer diameter of approximately 6-8 $\mathrm{nm}$ and can reach lengths up to tens of microns $[44,46,47,50,62-65]$. T4P are polymers of the type IV pilin, and cryo-EM [66-68] and fibre diffraction [69] analyses of T4P have demonstrated that T4P exhibit a three-start helical assembly of pilin monomers [44,62]. The type IV pilin monomer is comprised of a four-stranded antiparallel $\beta$-sheet wrapped around a hydrophobic $\alpha$-helix connected by a variable loop region [66,70-76]. Surface adherence and cell-host adhesion is mediated by a C-terminal loop known as the D-region, which is disulfide-bound in most pilins $[66,68,70-74,76]$, although the FimA pilin of Dichelobacter nodosus displays a conserved structure without the disulfide bond [75]. The observation that truncated pilins from $P$. aeruginosa strain K122-4 $(\Delta \mathrm{K} 122)$ could form PNTs morphologically similar to T4P in the presence of a hydrophobe $\left(\mathrm{C}_{11}-\mathrm{SH}\right)$, both in solution and when the hydrophobe was surface constrained [23,24], presents an interesting avenue for the development of bionano applications that target the T4P, for example pilus-specific biosensors.

Several studies highlight the potential applications of PNTs including targeted drug delivery systems, tissueengineering scaffolds and biosensing devices [35,38,77-83]. However, reports characterizing the assembly and properties of PNTs generated from full-length proteins in solution or at surfaces are more limited; it is in this light that we undertook the characterization of the oligomerization of pilin-derived PNTs in solution. Pilin-derived PNTs may have an advantage of being a more biologically accepted nanosystem when compared to their CNT counterparts. However in order to fully exploit PNTs for application development, a detailed understanding of their assembly and physical characteristics in solution and when surfaceconstrained is required. In the current study, we examine the assembly of $\Delta \mathrm{K} 122$-derived PNTs in solution, monitoring PNT oligomerization through liquid chromatography, multi-angle light scattering and negatively stained transmission electron microscopic methods. We identify an optimal trigger molecule, 2-methyl-2,4-pentanediol (MPD), characterize pilin oligomerization in solution, and discuss the assembly of $\Delta \mathrm{K} 122$-derived PNTs through intermediate pilin fibrils.

\section{Results and discussion}

The identification that monomeric pilins from $P$. aeruginosa oligomerized into PNTs [12,13,23] suggests that these structures could be adapted for a variety of applications. Previous studies, employing a polyclonal antibody that recognizes the $\mathrm{C}$-terminal region of the pilin from multiple strains of $P$. aeruginosa [84-86], have shown that the structure of and receptor binding properties of $\Delta \mathrm{K} 122$ are unaffected upon oligomerization into PNTs $[23,48,55]$. Furthermore, the observation that pilin-derived PNTs can assemble both in solution [23] and at surfaces [24,49] suggests that these structures could be adapted for applications such as biosensors and in bionanoelectronics while retaining several functional features associated with the native pilus itself.

Initial studies of pilin-derived PNTs in solution demonstrated that PNTs could be formed in the presence of long chain alkylthiols [23], and are stable in various aqueous buffers $[23,48,49,55]$. Surface studies have further demonstrated that longer chain alkanes are required for PNT oligomerization, although the hydrophobe is not incorporated into the PNT itself $[23,24,49,87]$. However, initial evidence suggested that smaller alkyl-chains could induce PNT oligomerization (GFA, unpublished observations). In order to assess the minimal hydrophobe required to initiate PNT oligomerization, freshly purified $\Delta \mathrm{K} 122\left(15 \mathrm{mg} \cdot \mathrm{mL}^{-1}\right)$ was incubated with a series of trigger molecules for 96 hours and analyzed using size exclusion chromatography (SEC). Each trigger molecule's ability to initiate PNT oligomerization was interrogated via the presence and height of the void volume peak relative to that of the $\Delta \mathrm{K} 122$ peak (Figure 1 ). PNT oligomerization is triggered by the "hydrophobic" component of the solution and not due to exposure to polypropylene of the microcentrifuge tubes during incubation or by buffer components themselves. When 


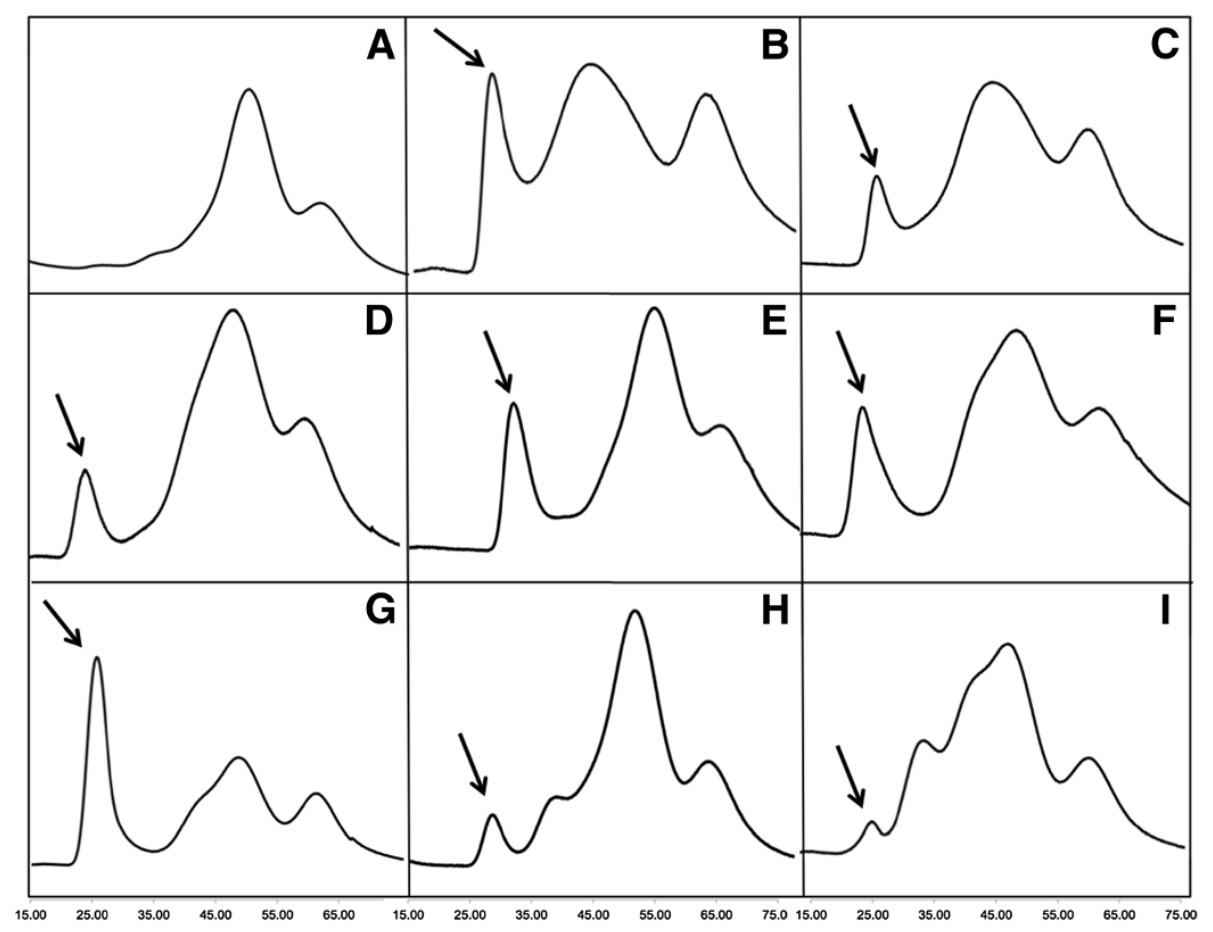

Figure 1 The effect of hydrophobic trigger molecules on PNT oligomerization in solution. SEC analysis (Sephadex G50 resin) of $15 \mathrm{mg} \cdot \mathrm{mL}^{-1}$ $\triangle \mathrm{K} 122$ incubated for 96 hours at room temperature with the addition of: (A) buffer only (10 mM Tris, $300 \mathrm{mM} \mathrm{NaCl}, 1 \mathrm{mM}$ EDTA, 1 mM DTT, pH 7.4; no additives); (B) the hydrophobic trigger solution as reported by Audette et al. (1-undecanethiol, 1-propanol, methanol, DTT, EDTA, pH 6.4) [23]; panels C through I are buffer with the addition of 1-undecanethiol (C), 1-tetradecanethiol (D), methanol (E), 1-propanol (F), 2-methyl-2,4-pentanediol (G) and PEG 3350 (H) or PEG 8000 (I). All chromatograms are on a common vertical scale, and the effectiveness of each compound to initiate pilin oligomerization was evaluated by the appearance of the high molecular weight peak indicated with an arrow in each panel versus the concurrent decrease in the peak associated with the $\Delta \mathrm{K} 122$ monomer (panel $\mathbf{A}$ ).

incubated in buffer alone, no high molecular weight protein peak is observed (Figure 1A). Comparatively, when incubated with the original "hydrophobe solution", a significant PNT peak is observed (Figure 1B). As expected, when incubated with either 1-undecanethiol (Figure 1C) or 1-tetradecanethiol (Figure 1D) alone in buffer, PNT oligomerization is observed. However, in both cases, PNT oligomerization is less than that observed when comparing to the original hydrophobe solution (Figure 1B). This is likely due to the low solubility of both $\mathrm{C}_{11}-\mathrm{SH}$ and $\mathrm{C}_{14}-\mathrm{SH}$. The addition of 1-propanol and methanol in the original PNT trigger solution greatly increased the aqueous solubilisation of the alkylthiol allowing for increased interaction with the protein, which in turn increased PNT formation. Interestingly, both methanol (Figure 1E) and 1propanol (Figure 1F) alone in buffer were able to trigger PNT oligomerization. In both cases, the PNT peaks are larger than those seen with either $\mathrm{C}_{11}-\mathrm{SH}$ or $\mathrm{C}_{14}-\mathrm{SH}$, again indicating that solubility of the hydrophobic trigger molecule in the aqueous buffer is critical for initiation of PNT oligomerization.

The most effective trigger compound for the oligomerization of $\triangle \mathrm{K} 122$ PNTs was found to be 2-methyl-2,4pentanediol (MPD) (Figure 1G). MPD had been expected to behave similarly to 1-propanol in its ability to trigger PNT oligomerization. This is because the presence of the second hydroxyl group in MPD increases its hydrophilicity despite containing 2 more methylene groups than propanol. This increased hydrophilicity enables MPD to more effectively interact with proteins in solution and is therefore often used in protein crystallization [88]. In fact, the PNT peak associated with the incubation of $\Delta \mathrm{K} 122$ with MPD is larger than any of the other samples, both in peak height as well as its ratio to the monomeric $\Delta K 122-4$ peak (Figure 1). This indicates that the added solubility due to the second hydroxyl of MPD adds sufficient hydrophilicity for a more favorable interaction with the $\Delta \mathrm{K} 122$ monomer in order to initiate PNT oligomerization. In contrast to MPD, exposure of the protein to polyethylene glycol (PEG) 3350 (Figure 1H) or PEG 8000 (Figure 1I) shows very little PNT oligomerization. PEGs are also frequently used in protein crystallization $[88,89]$, and have been shown to reduce non-specific adsorption of proteins to implantable devices [90]. These data are important for the future development of PNT-containing nanodevices where the bio-nonfouling nature of PEG additives as surface coatings is exploited for increasing implantable device lifetimes in the body [91]. The lack of PNT 
oligomerization with PEGs may allow the pre-functionalization of surfaces with PEGs and exposed hydrophobes for site-localized PNT oligomerization; we are currently examining this possibility.

Previous studies of $\Delta \mathrm{K} 122$ PNT formation [23,87] showed the appearance of a peak with a retention time longer than that of the monomeric pilin. A peak with a longer retention time was also observed when studying the optimal trigger molecule for PNT oligomerization (Figure 1). It has been suggested that this longer retention SEC peak was a result of a $\Delta \mathrm{K} 122$ pilin fibril that interacted abnormally with the chromatographic resin [23]. The presence of a pilin fibril would be consistent with both initial TEM studies of PNTs, where the PNTs were observed to "fray" [23], as well as current threestart T4P assembly models $[44,62,67]$. In order to clarify the oligomerization process, and identify this predicted pilin fibril, we monitored the oligomerization of $\Delta \mathrm{K} 122$ in solution over time on a high-resolution silica-based SEC column (Figure 2). Starting with the initial $\Delta K 122$ solution $\left(1 \mathrm{mg} \cdot \mathrm{mL}^{-1}\right)$, incubation with the MPD initiator resulted in a decrease in the peak height associated with the $\Delta \mathrm{K} 122$ monomer, with a concurrent increase in peak heights of peaks associated with higher molecular weight species (Figure 2, Peak 1 vs. Peaks 2 \& 3). The presence of higher molecular weight species (Peaks 2 and 3) can be observed in as early as 3 hours (brown trace). Comparison of relative peak areas indicates that at 3 hours incubation, the monomeric form of $\Delta K 122$ decreases from $82.5 \%$ to $44.8 \%$ total species present, while the higher molecular weight species increase from $17.5 \%$ to $55.1 \%$ (Figure 2, inset table). The higher molecular weight species continue to accumulate over 24 (red trace) and 72 (green trace) hours, resulting in the higher molecular weight species accounting for $90 \%$ of the total protein present in solution after 72 hours. Of the resulting overall $90 \%$ total protein, an average of $23.5 \%$ remains in the middle range (Peak 2), suggesting that the process of PNT oligomerization is likely dependent upon the initial formation of an intermediate species (Peak 2) that then form PNTs (Peak 3) over time. It was also noted that the peak corresponding to the $\Delta \mathrm{K} 122$ monomer (Peak 1) does not fully disappear over the process of PNT formation, remaining at $\sim 10 \%$ of the protein present after 72 hours incubation. A possible explanation for this is that there is an equilibrium between the $\Delta \mathrm{K} 122$ and nascent fibrils prior to incorporation into full PNTs.

At incubation times up to 24 hours, the presence of a shoulder on the high molecular weight SEC peak (Figure 2; red trace) was noted, suggesting multiple high molecular weight species were present in solution. To assess the species present in solution during the assembly of PNTs from monomeric $\triangle \mathrm{K} 122$, SEC separated samples were subjected to multi-angle light scattering (MALS) analysis following SEC separation (Figure 3A). The protein

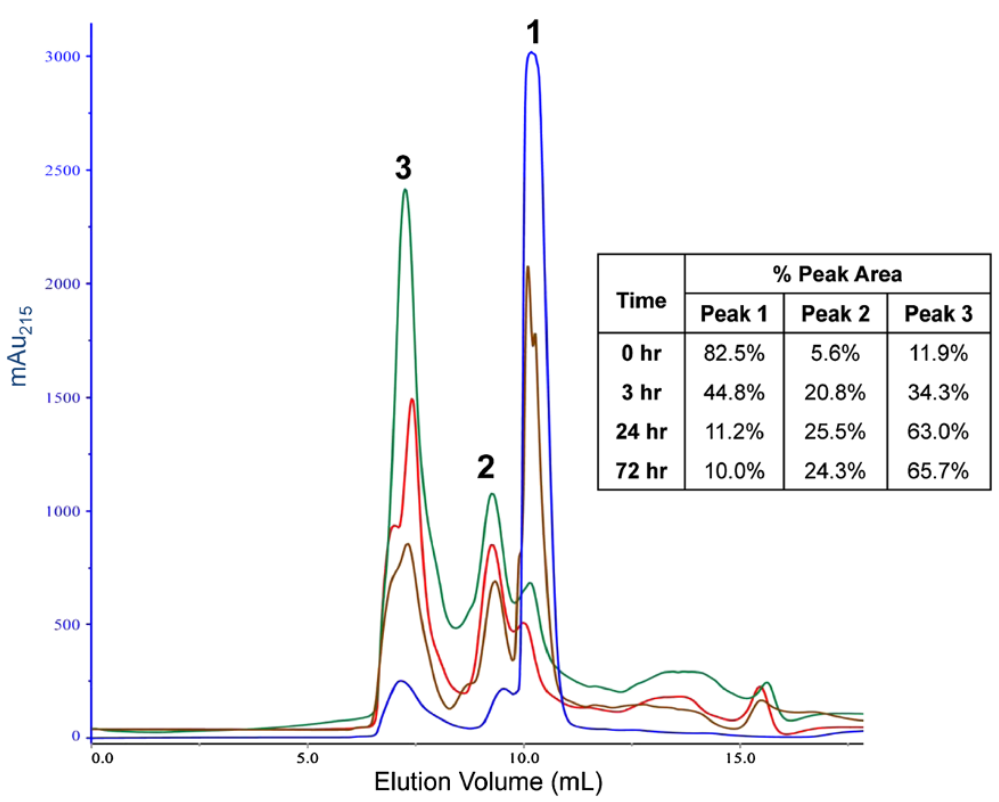

Figure 2 Monitoring $\Delta$ K122 PNT generation over time. SEC analysis (10 nm pore size) of $1 \mathrm{mg} \cdot \mathrm{mL}^{-1} \Delta \mathrm{K} 122$ (blue) incubated with MPD in oligomerization buffer for 3 hours (brown), 24 hours (red) or 72 hours (green). The peak associated with $\Delta$ K122 (Peak 1) decreased over time with the appearance and increase in height of peaks associated with higher molecular weight species (Peaks 2 and 3). The relative areas of these peaks were integrated (inset table) to assess PNT oligomerization over time. The peaks were further characterized by MALS and TEM (Figure 3; Table 1) and identified as pilin-derived nanofibrils (Peak 2) and PNTs (Peak 3). 

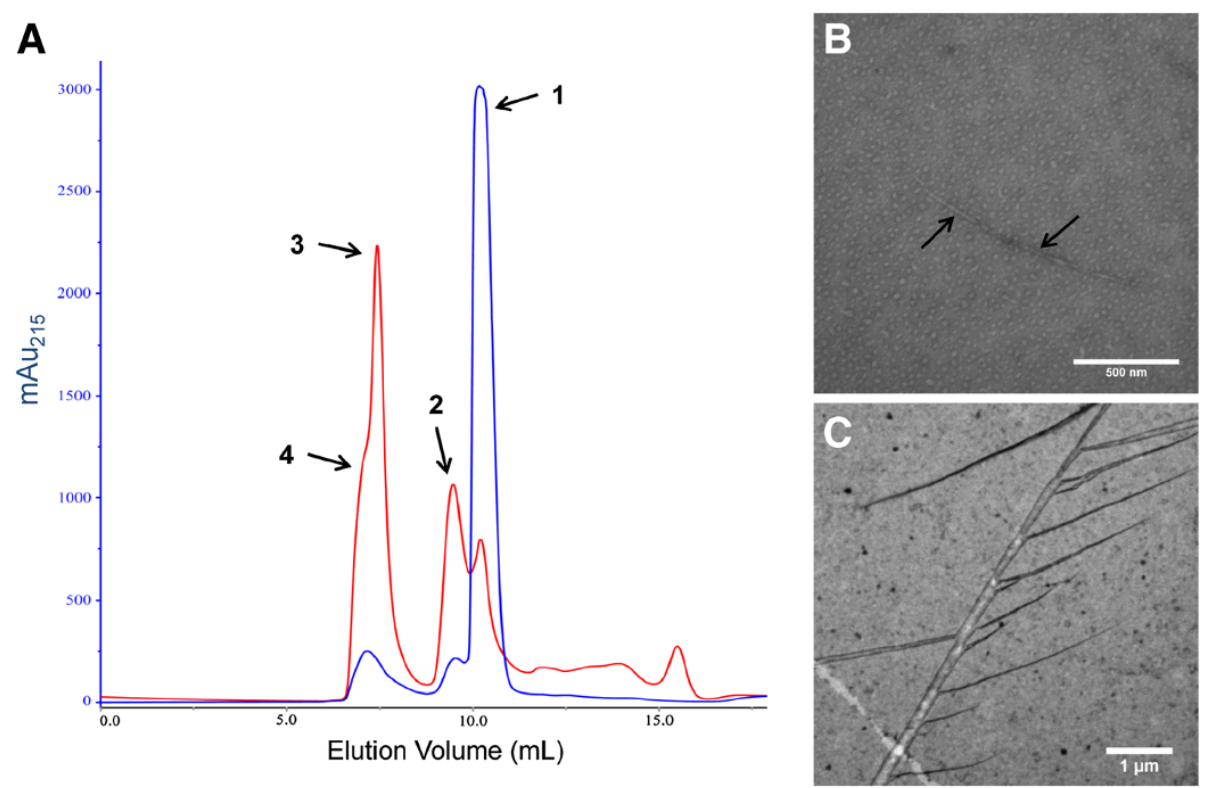

Figure 3 Characterizing the process of $\Delta \mathrm{K} 122 \mathrm{PNT}$ oligomerization in solution. (A) SEC analysis (10 nm pore size) of $1 \mathrm{mg} \cdot \mathrm{mL}^{-1} \Delta \mathrm{K} 122$ before (blue) and after (red) $24 \mathrm{hr}$ incubation with MPD. Peaks 1 through 4 were analyzed with multi-angle light scattering in-line with the SEC (SEC-MALS; Table 1). SEC-MALS data indicate that $\triangle K 122$ exists in a monomer/dimer equilibrium (Peak 1) and that upon incubation with MPD, higher molecular weight species form, corresponding to 14, 20 and 40 pilin monomers for Peaks 2, 3 and 4, respectively (Table 1). Aliquots of SEC-separated $\triangle \mathrm{K} 122\left(15 \mathrm{mg} \cdot \mathrm{mL}^{-1}\right)$ incubated with MPD for $24 \mathrm{hr}$ corresponding to Peaks $1 / 2$ and $3 / 4$ were negatively stained with $4 \%$ uranyl acetate and visualized with TEM. (B) The $\triangle K 122$ monomer/dimers in Peaks $1 / 2$ are seen as aggregates in TEM, and form pilin fibrils (highlighted by arrows) upon addition of the oligomerization initiator MPD to the protein solution. (C) Pilin fibrils associate into PNTs (Peaks 3/4), which can then coalesce into larger PNT bundles that show similar structures as those formed when $\mathrm{C}_{11}$-SH is used as the inducer of pilin oligomerization $[23,87]$.

species' weight-averaged molar mass $\left(\mathrm{M}_{\mathrm{w}}\right)$ and other relevant MALS data are presented in Table 1. Multiple molar mass values are reported from MALS experiments, including the number-averaged $\left(M_{n}\right)$ and weight-averaged $\left(\mathrm{M}_{\mathrm{w}}\right)$ molar mass; the ratio of $\mathrm{M}_{\mathrm{w}} / \mathrm{M}_{\mathrm{n}}$ (polydispersity index) is an indication of the heterogeneity of the species being analyzed [92,93]. When $M_{w} / M_{n}$ differs from unity, the species is a more polydisperse mixture and $M_{W}$ is a generally more reliable assessment of the molecular mass of the species present. It can be seen from Table 1 that the all peaks analyzed (Figure $3 \mathrm{~A}$ ) show $\mathrm{M}_{\mathrm{w}} / \mathrm{M}_{\mathrm{n}}$ ratios indicating the presence of multiple species in each peak. Analysis of the peak corresponding to "monomeric" $\Delta \mathrm{K} 122$ shows a MALS-determined $\mathrm{M}_{\mathrm{w}}$ of $26.5 \pm 1.2 \mathrm{kDa}$ and hydrodynamic radius $\left(R_{h}\right)$ of $4.32 \pm 0.11 \mathrm{~nm}$. While the $R_{h}$ of the pilin correlates with that known from the crystallographic structures of the $\Delta K 122$ pilin [71], the MALS-determined $M_{w}$ was unexpected. Taking into consideration that the known molecular weight of $\Delta \mathrm{K} 122$ is $12,837.57 \mathrm{Da}$ [94], and that both crystallographically determined structures of $\Delta \mathrm{K} 122$ have dimers with their asymmetric unit [71], these data indicate that the $\Delta \mathrm{K} 122$ pilin exists in a monomer-dimer equilibrium prior to initiation of PNT oligomerization. In addition, electro-spray mass spectrometric analysis of $\Delta \mathrm{K} 122$ also suggests a mono- mer-dimer equilibrium and that pilin dimers come together to form larger species after addition of the MPD trigger (D. Yong et al., in preparation). Furthermore, noting the generally low solubility of full-length pilins due to the presence of the hydrophobic N-terminal $\alpha$-helix $[66,70,75]$, and that long-standing solutions of $\Delta \mathrm{K} 122$ appear to form gels in microfuge tubes (data not shown), the observation of a monomer-dimer equilibrium of $\Delta \mathrm{K} 122$ in solution is not unexpected. SEC-MALS analysis of $\triangle \mathrm{K} 122$ following 24 hours incubation with MPD shows several higher molecular weight species present in solution (Figure 3A, Peaks 2-4; Table 1). The protein species within these peaks were relatively mobile, with translational diffusion $\left(D_{t}\right)$ coefficients and $R_{h}$ values similar to that observed for the $\Delta \mathrm{K} 122$ monomer/dimer (Table 1; Peak 1), however the $\mathrm{Mw}$ determined for each peak suggests that these species are composed of increasing amounts of $\Delta \mathrm{K} 122$. With an observed $\mathrm{M}_{\mathrm{w}}$ of $183.6 \pm 17.4$ $\mathrm{kDa}$, the species within Peak 2 (Figure $3 \mathrm{~A}$ ) would contain fourteen $\Delta \mathrm{K} 122$ monomers; the species in Peaks 3 and 4 would be composed of approximately twenty and forty monomers, respectively.

In order to observe the species identified by SECMALS analysis, aliquots of SEC-separated $\triangle \mathrm{K} 122$ pilin $\left(15 \mathrm{mg} \cdot \mathrm{mL}^{-1}\right)$ after 24 hours incubation with MPD 
Table 1 SEC-MALS analysis of $\Delta K 122$ oligomerization

\begin{tabular}{lcccc}
\hline & Peak 1 $^{*}$ & Peak 2 & Peak 3 & Peak 4 \\
\hline $\mathbf{M}_{\mathbf{w}}$ (kDa) & $26.5 \pm 1.2$ & $183.6 \pm 17.4$ & $256.7 \pm 37.7$ & $520.7 \pm 146.3$ \\
$\mathbf{M}_{\mathbf{w}} / \mathbf{M}_{\mathbf{n}}$ & $1.11 \pm 0.07$ & $1.27 \pm 0.22$ & $1.71 \pm 0.46$ & $1.16 \pm 0.49$ \\
$\mathbf{R}_{\mathbf{h}}$ (nm) & $4.32 \pm 0.11$ & $4.20 \pm 0.13$ & $3.9 \pm 0.1$ & $4.1 \pm 0.1$ \\
$\begin{array}{l}\text { Dt (x10 } \\
\left.\mathbf{c m}^{\mathbf{2}} \mathbf{s}^{-\mathbf{- 1}}\right)\end{array}$ & $5.82 \pm 0.15$ & $6.10 \pm 0.22$ & $6.6 \pm 0.2$ & $6.15 \pm 0.2$ \\
\hline
\end{tabular}

*Peaks analyzed as indicated in Figure 3A.

corresponding to Peaks $1 / 2$ and $3 / 4$ were negatively stained with $4 \%$ uranyl acetate, visualized with TEM (Figure 3B, C), and compared to that PNTs oligomerized using the original $\mathrm{C}_{11}-\mathrm{SH}$ hydrophobe as the inducer $[23,87]$. TEM analysis of a Peak $1 / 2$ aliquot (Figure 3B) show pilin fibrils (highlighted with arrows) interspersed among a general aggregation of the $\Delta \mathrm{K} 122$ monomers/ dimers. The components of a Peak 3/4 aliquot shows the presence of full PNTs (Figure 3C), consistent with previous observations of pilin-derived PNTs in solution [23] and at surfaces [24]. MALS analysis of this Peak 3/4 aliquot was challenging due to the high protein concentration $\left(15 \mathrm{mg} \cdot \mathrm{mL}^{-1}\right)$ resulting in signal overload at the detector. However a MALS-determined $\mathrm{M}_{\mathrm{w}}$ of 51,610 \pm $4,900 \mathrm{kDa}$ was observed for the species in this SECseparated aliquot. This $\mathrm{M}_{\mathrm{w}}$ corresponds to a structure that is microns in length containing $4040 \Delta \mathrm{K} 122$ monomers, a structure which is observed in the TEM analysis of the Peak 3/4 aliquot (Figure 3C). Pilin-derived PNTs were also observed to further bundle into larger structures where PNT bundles ranging in width from $~ 25-65$ $\mathrm{nm}$ (Figure 3C) to greater than $250 \mathrm{~nm}$ in crosssection [95]. Given the predicted outer diameter of $\sim 6 \mathrm{~nm}$ for native T4P $[44,46,62,63,66,67,69]$ and/or K122-derived PNTs [12,23,24], the observed structures would correspond to bundles of $\sim 4-11$ PNTs.

T4P assembly/disassembly is achieved via a multiprotein membrane associated complex in a highly coordinated fashion $[46,47,50,60,62,64,65,67]$. However PNTs derived from truncated $\Delta \mathrm{K} 122$ monomers do not have such a protein system to guide PNT assembly, nor do they have the conserved N-terminal region of the $\alpha$ helix to hydrophobically drive pilin oligomerization. It is therefore not surprising that multiple species (monomers, dimers, multimers) are present in solution during PNT oligomerization. Indeed, SEC-MALS analysis of the MPD-initiated $\triangle \mathrm{K} 122$ PNT formation (Table 1) shows that multiple species are present in solution. These multiple species are difficult to separate chromatographically as they reach higher molecular weights, however SECMALS data suggests that the species are likely multiples of dimers (Table 1). In addition, the observation of an initial $\Delta \mathrm{K} 122$ monomer/dimer in solution (Figure 3A, B; Table 1) is not unprecedented knowing that both crystallographic structures of $\Delta \mathrm{K} 122$ show two pilin molecules within their respective asymmetric units [71]. Upon addition of the MPD trigger to the protein, $\Delta \mathrm{K} 122$ monomer/dimers would oligomerize into extended fibrils, which then can come together to form PNTs (Figure 4). If the $\Delta$ K122 PNTs oligomerized via a one-start mechanism as was initially suggested [23], one would expect ring-like structures when analyzing the contents of the intermediate molecular weight species (Figure 2, Peak 2). However a more extended structure, rather than protein rings, was observed (Figure 3B) for the intermediate pilin fibrils. When the pilin fibrils are of sufficient length, they then coalesce into PNTs that have the characteristic three-start helical symmetry seen in native T4P (Figure 4) while retaining the native structure and binding characteristics of pilins within the T4P $[23,48,55]$. The exact mechanism of this fibril coalescence is at this time unclear, however it may be possible that stabilization of the truncated pilin dimer and fibril is achieved through involvement of the $\alpha$ helix. A comparison of the crystal [71] and NMR [73] structures of $\Delta K 122$ revealed that the $\alpha$-helix of the pilin was less tightly packed on the $\beta$-sheet of the pilin in the NMR structure [71], suggesting some flexibility prior T4P assembly. Noting that there are some arguments in favour of a less rigid packing of the $\beta$-sheet onto the $\alpha$-helix in the T4P [96], it is possible that the truncated $\alpha$-helix of $\Delta K 122$ shifts to increase helix-helix interactions in the dimer/fibril and thereby impart increased stability to the nascent fibril prior to coalescence into PNTs. Furthermore, as native T4P are known to bundle on surfaces for coordinated motion and biofilm formation [47,50,58-60], the observation that pilin-derived PNTs also further associate and form larger bundle-like structures (Figure 3C) was expected. Research in our lab is ongoing to fully elucidate the mechanisms by which the $\Delta \mathrm{K} 122$ pilin stabilizes the nascent fibril and to form PNTs, as well as determine the parameters of PNT bundle formation and identify how one may isolate a single PNT from a formed bundle either in solution or at surfaces.

\section{Conclusions}

The development of protein-based nanotubes for biologically based nanosystems is receiving increased interest due to their richness in structural diversity, adaptability through protein engineering approaches and inherent biocompatibility. The adaptation of the T4P as protein nanotubes through engineered type IV pilin monomers has shown distinct promise in that these structures can assemble both in solution and at surfaces in a template independent fashion $[23,24,49,87,95]$. In the current report, we have shown that the $\Delta \mathrm{K} 122$ pilin is in a monomer-dimer equilibrium in solution, and that oligomerization of the pilin can be induced from short alkyl chains in solution, however optimal oligomerization is achieved when MPD 


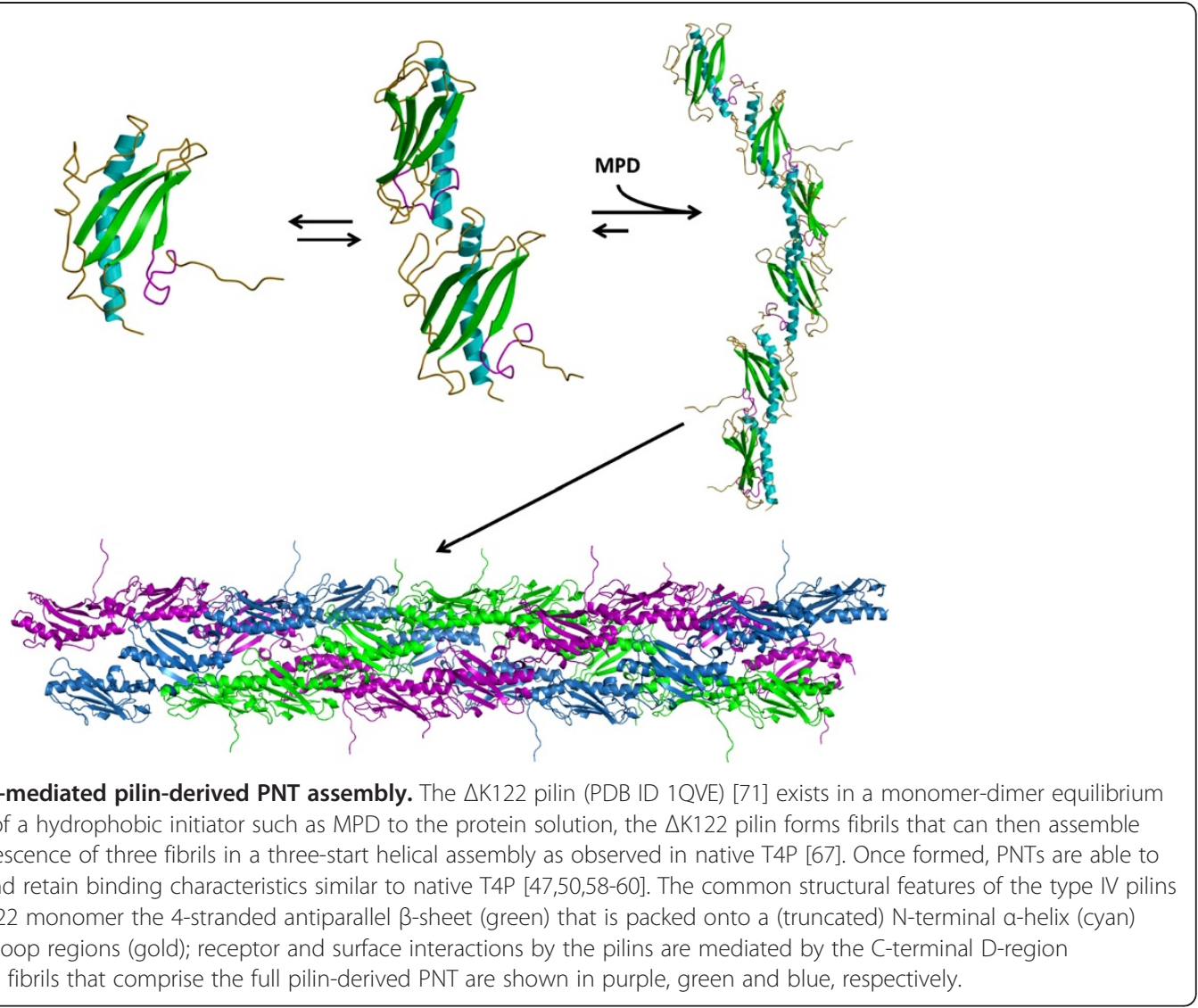

is used as an initiator (Figure 1). Upon addition of the MPD initiator to the $\triangle \mathrm{K} 122$ solution, the protein forms fibrils that then assemble into full length PNTs (Figures 2, 3), although the exact assembly mechanism is at this time unclear. Research in our group is on going to further characterize $\Delta \mathrm{K} 122$-derived PNT assembly (both in solution and at surfaces), understand the structural and mechanistic requirements of PNT oligomerization and fibril stabilization, and to develop these structures for applications as bionanowires and biosensors.

\section{Methods}

\section{Expression and purification of $\Delta \mathrm{K} 122$}

The truncated form of the monomeric type IV pilin from $P$. aeruginosa strain K122-4 [pilA ( $\Delta 1-28) ; \Delta K 122]$ was expressed and purified as previously reported $[23,24,71,94]$. The $\Delta \mathrm{K} 122$ pilin was purified as an MBPfusion construct and isolated from the MBP tag via cation exchange chromatography using a linear gradient of $0-1 \mathrm{M} \mathrm{NaCl}$ in $10 \mathrm{mM}$ Tris ( $\mathrm{pH}$ 7.4) following trypsin digestion of the MBP- $\Delta \mathrm{K} 122$ fusion protein (500:1 protein:trypsin ratio; $10 \mathrm{~min}$ on ice). Freshly purified, monomeric $\Delta \mathrm{K} 122$ pilin was concentrated to $15 \mathrm{mg} \cdot \mathrm{mL}^{-1}$ or diluted to $1 \mathrm{mg} \cdot \mathrm{mL}^{-1}$ as appropriate and used for all oligomerization experiments. All experiments conducted in this study were reviewed and approved by the York University's Biological Safety Committee, the institutional body responsible for oversight of such research.

\section{Determination of an optimal trigger of $\Delta \mathrm{K} 122$ oligomerization in solution}

The initially reported solution for initiating oligomerization was composed of $1.1 \mathrm{M}$ 1-undecanethiol $\left(\mathrm{C}_{11}-\mathrm{SH}\right)$ in methanol containing $1 \mathrm{mM}$ EDTA, $1 \mathrm{mM}$ dithiothreitol (DTT) at $\mathrm{pH}$ 6.4 [23]. Studies of PNT oligomerization from surfaces suggest that the initiation of PNT assembly could be achieved with smaller chain alkylthiols, and/or mixtures thereof $[24,87]$. Characterization of an optimal trigger molecule in solution was conducted by incubating $15 \mathrm{mg} \cdot \mathrm{mL}^{-1} \Delta \mathrm{K} 122$ with buffer (10 mM Tris, $300 \mathrm{mM} \mathrm{NaCl}, 1 \mathrm{mM}$ EDTA, $1 \mathrm{mM}$ DTT, $\mathrm{pH}$ 7.4) alone, or with buffer plus methanol (3.2 M), 1propanol $(1.7 \mathrm{M})$, 1-undecanethiol $\left(\mathrm{C}_{11}-\mathrm{SH}, 0.6 \mathrm{M}\right), 1$ tetradecanethiol $\left(\mathrm{C}_{14}-\mathrm{SH}, 0.5 \mathrm{M}\right), 2,4$-methylpentanediol (MPD, $1.0 \mathrm{M}$ ), polyethylene glycol 3350 (PEG 3350, 6.5\% $(\mathrm{w} / \mathrm{v})$ ) or polyethylene glycol 8000 (PEG 8000, 6.5\% $(\mathrm{w} / \mathrm{v})$ ) (Figure 1). PNT oligomerization was initiated through the addition of the trigger solution to $\Delta \mathrm{K} 122$ in a $10: 1(\mathrm{v} / \mathrm{v})$ protein to hydrophobe ratio, and the $\Delta \mathrm{K} 122$ trigger solution was incubated at room temperature with 
nutation for 96 hours. PNT oligomerization was monitored using size exclusion chromatography (SEC) on a G50 Sephadex column (separation range $1.5 \mathrm{kDa}-30$ $\mathrm{kDa}$, standardized with blue Dextran $2000, \mathrm{~V}_{0} / \mathrm{V}_{\text {Total }}=$ 17.23/49.9l mL) on an Akta Purifier (GE Healthcare) at a flow rate of $1 \mathrm{~mL} \cdot \mathrm{min}^{-1}$.

\section{Multi-angle light scattering of $\Delta \mathrm{K} 122$ oligomerization} The oligomerization of $1 \mathrm{mg} \cdot \mathrm{mL}^{-1} \Delta \mathrm{K} 122$ triggered with MPD in buffer was analyzed using SEC and multi-angle light scattering (MALS) using an Akta Purifier 10 (GE Healthcare) connected in-line to a Dawn Heleos II and Optilab T-rEX light scattering system (Wyatt Technology) (Figure 2, 3). Analysis of $100 \mu \mathrm{L}$ protein samples was performed at a flow rate of $0.5 \mathrm{~mL} \mathrm{~min}^{-1}$ in SEC buffer (10 mM Tris, pH 7.4) on a silica-based column (Wyatt Technology, $10 \mathrm{~nm}$ pore size, separation range $100 \mathrm{Da}-100 \mathrm{kDa}, \mathrm{V}_{\text {Total }}=10.71 \mathrm{~mL}$ ). After chromatographic separation, the column eluate traveled to the MALS flow cell where light scattering $(658 \mathrm{~nm}$ laser light source) of the separated species was monitored by 15 angularly separated static light scattering detectors and a quasi-elastic light scattering (QELS) detector at a collection angle of $100.2^{\circ}$ (Figure 3A; Table 1). Hydrodynamic radii $\left(R_{h}\right)$ and diffusion coefficients $\left(D_{t}\right)$ were calculated from an autocorrelation function using the accompanying Astra 6 software package (Table 1).

\section{Transmission electron microscopy}

Transmission electron microscopy (TEM) of SEC-MALS separated PNTs was conducted in the Department of Biology's Core Imaging Facility at York University, and samples for TEM analysis were prepared as follows. Ten microlitre aliquots of PNT solutions were dispensed onto plastic-coated nickel mesh grids and allowed to dry in air for $10 \mathrm{~min}$; any remaining liquid was carefully removed by blotting with filter paper. Samples were stained with a $4 \%$ aqueous uranyl acetate, which was added to the grid and allowed to incubate for 10 minutes at room temperature, following which excess stain was removed by blotting with filter paper. Samples were imaged using a Philips 210 Transmission Electron Microscope operating at an accelerating voltage of $60 \mathrm{kV}$, and images visualized using the ImageJ software package [97].

\footnotetext{
Abbreviations

PNTs: Protein nanotubes; $\triangle K 122$ : The truncated pilin from $P$. aeruginosa strain K122-4; SEC: Size exclusion chromatography, MALS, multi-angle light scattering; TEM: Transmission electron microscopy; MPD: 2-methyl-2,4-pentanediol.
}

\section{Competing interests}

The authors declare that they have no competing interests.

\section{Author contributions}

The manuscript was written through contributions of all authors. All authors have given approval to the final version of the manuscript.

\section{Acknowledgements}

This research was supported by grants to GFA from the Natural Sciences \& Engineering Council of Canada (NSERC), the Canadian Foundation for Innovation (CFI) and York University. AP and SL acknowledge financial support from the Ontario Graduate Scholarship Program, NSERC and York University. The authors acknowledge technical assistance by Ms. Karen Rethoret (Dept. of Biology, York University) for TEM studies.

Received: 3 May 2013 Accepted: 1 July 2013

Published: 5 July 2013

\section{References}

1. Huczko A, Lange H, Bystrzejewski M, Baranowski P, Grubek-Jaworska H, Nejman P, Przybyłowski T, Czumińska K, Glapiński J, Walton DRM, Kroto HW: Pulmonary Toxicity of 1-D Nanocarbon Materials. Fullerenes, Nanotubes and Carbon Nanostructures 2005, 13:141-145.

2. Magrez A, Kasas S, Salicio V, Pasquier N, Seo JW, Celio M, Catsicas S, Schwaller B, Forró L: Cellular Toxicity of Carbon-Based Nanomaterials. Nano Lett 2006, 6:1121-1125.

3. Smart SK, Cassady Al, Lu GQ, Martin DJ: The biocompatibility of carbon nanotubes. Carbon 2006, 44:1034-1047.

4. Cui D, Tian F, Ozkan CS, Wang M, Gao H: Effect of single wall carbon nanotubes on human HEK293 cells. Toxicol Lett 2005, 155:73-85.

5. Muller J, Huaux F, Moreau N, Misson P, Heilier J-F, Delos M, Arras M, Fonseca A, Nagy JB, Lison D: Respiratory toxicity of multi-wall carbon nanotubes. Toxicol Appl Pharmacol 2005, 207:221-231.

6. Shvedova A, Castranova V, Kisin E, Schwegler-Berry D, Murray A, Gandelsman V, Maynard A, Baron P: Exposure to Carbon Nanotube Material: Assessment of Nanotube Cytotoxicity using Human Keratinocyte Cells. J Toxicol Environ Health A 2003, 66:1909-1926.

7. Jia G, Wang H, Yan L, Wang X, Pei R, Yan T, Zhao Y, Guo X: Cytotoxicity of Carbon Nanomaterials: Single-Wall Nanotube, Multi-Wall Nanotube, and Fullerene. Environ Sci Technol 2005, 39:1378-1383.

8. Oberdörster G, Oberdörster E, Oberdörster J: Nanotoxicology: An Emerging Discipline Evolving from Studies of Ultrafine Particles. Environ Health Perspect 2005, 113:823-839.

9. Aillon KL, Xie Y, El-Gendy N, Berkland CJ, Forrest ML: Effects of nanomaterial physicochemical properties on in vivo toxicity. Adv Drug Del Rev 2009, 61:457-466.

10. Li X, Gao H, Uo M, Sato Y, Akasaka T, Feng Q, Cui F, Liu X, Watari F: Effect of carbon nanotubes on cellular functions in vitro. J Biomed Mater Res $A$ 2009, 91A:132-139.

11. Li $X$, Fan $Y$, Watari F: Current investigations into carbon nanotubes for biomedical application. Biomed Mater 2010, 5:022001.

12. Audette GF, Hazes B: Development of Protein Nanotubes from a MultiPurpose Biological Structure. J Nanoci Nanotechnol 2007, 7:2222-2229.

13. Petrov A, Audette GF: Peptide and protein-based nanotubes for nanobiotechnology. WIREs Nanomed Nanobiotechnol 2012, 4:575-585.

14. Nishiyama N: Nanomedicine: Nanocarriers shape up for long life. Nat Nano 2007, 2:203-204.

15. Geng Y, Dalhaimer P, Cai S, Tsai R, Tewari M, Minko T, Discher DE: Shape effects of filaments versus spherical particles in flow and drug delivery. Nat Nano 2007, 2:249-255.

16. Champion J, Walker A, Mitragotri S: Role of Particle Size in Phagocytosis of Polymeric Microspheres. Pharm Res 2008, 25:1815-1821.

17. Valéry C, Pouget E, Pandit A, Verbavatz J-M, Bordes L, Boisdé I, Cherif-Cheikh R, Artzner F, Paternostre M: Molecular Origin of the Self-Assembly of Lanreotide into Nanotubes: A Mutational Approach. Biophys J 2008, 94:1782-1795.

18. Xu H, Das AK, Horie M, Shaik MS, Smith AM, Luo Y, Lu X, Collins R, Liem SY, Song A, et al: An investigation of the conductivity of peptide nanotube networks prepared by enzyme-triggered self-assembly. Nanoscale 2010, 2:960-966.

19. Ashkenasy N, Horne WS, Ghadiri MR: Design of Self-Assembling Peptide Nanotubes with Delocalized Electronic States. Small 2006, 2:99-102.

20. Reches M, Gazit E: Casting Metal Nanowires Within Discrete Self-Assembled Peptide Nanotubes. Science 2003, 300:625-627.

21. Kumara MT, Srividya N, Muralidharan S, Tripp BC: Bioengineered Flagella Protein Nanotubes with Cysteine Loops: Self-Assembly and Manipulation in an Optical Trap. Nano Lett 2006, 6:2121-2129. 
22. Kumara MT, Tripp BC, Muralidharan S: Layer-by-Layer Assembly of Bioengineered Flagella Protein Nanotubes. Biomacromolecules 2007, 8:3718-3722.

23. Audette GF, VanSchaik EJ, Hazes B, Irvin RT: DNA-Binding Protein Nanotubes: Learning from Nature's Nanotech Examples. Nano Lett 2004, 4:1897-1902.

24. Lombardo S, Jasbi SZ, Jeung S-K, Morin S, Audette GF: Initial Studies of Protein Nanotube Oligomerization from a Modified Gold Surface. J Bionanosci 2009, 3:61-65.

25. Ballister ER, Lai AH, Zuckermann RN, Cheng Y, Mougous JD: In vitro self-assembly of tailorable nanotubes from a simple protein building block. Proc Natl Acad Sci USA 2008, 105:3733-3738.

26. Miranda FF, Iwasaki K, Akashi S, Sumitomo K, Kobayashi M, Yamashita I, Tame JRH, Heddle JG: A Self-Assembled Protein Nanotube with High Aspect Ratio. Small 2009, 5:2077-2084.

27. Tao C, Yang S, Zhang J: Template-synthesized Protein Nanotubes with Controlled Size Based on Layer-by-layer Method. Chin J Chem 2010, 28:325-328.

28. Komatsu T, Terada H, Kobayashi N: Protein Nanotubes with an Enzyme Interior Surface. Chemistry - A European Journal 2011, 17:1849-1854.

29. Tian Y, He Q, Cui Y, Li J: Fabrication of Protein Nanotubes Based on Layer-by-Layer Assembly. Biomacromolecules 2006, 7:2539-2542.

30. Mukherjee S, Pfeifer CM, Johnson JM, Liu J, Zlotnick A: Redirecting the Coat Protein of a Spherical Virus to Assemble into Tubular Nanostructures. J Am Chem Soc 2006, 128:2538-2539.

31. Miller RA, Presley AD, Francis MB: Self-Assembling Light-Harvesting Systems from Synthetically Modified Tobacco Mosaic Virus Coat Proteins. J Am Chem Soc 2007, 129:3104-3109.

32. Balci S, Bittner AM, Hahn K, Scheu C, Knez M, Kadri A, Wege C, Jeske H, Kern K: Copper nanowires within the central channel of tobacco mosaic virus particles. Electrochim Acta 2006, 51:6251-6257.

33. Balci S, Bittner AM, Schirra M, Thonke K, Sauer R, Hahn K, Kadri A, Wege C, Jeske $\mathrm{H}$, Kern $\mathrm{K}$ : Catalytic coating of virus particles with zinc oxide. Electrochim Acta 2009, 54:5149-5154.

34. Huang Y, Chiang C-Y, Lee SK, Gao Y, Hu EL, Yoreo JD, Belcher AM: Programmable Assembly of Nanoarchitectures Using Genetically Engineered Viruses. Nano Lett 2005, 5:1429-1434.

35. Nam KT, Kim D-W, Yoo PJ, Chiang C-Y, Meethong N, Hammond PT, Chiang Y-M, Belcher AM: Virus-Enabled Synthesis and Assembly of Nanowires for Lithium Ion Battery Electrodes. Science 2006, 312:885-888.

36. Nam KT, Wartena R, Yoo PJ, Liau FW, Lee YJ, Chiang Y-M, Hammond PT, Belcher AM: Stamped microbattery electrodes based on self-assembled M13 viruses. Proc Natl Acad Sci 2008, 105:17227-17231.

37. Nam YS, Park H, Magyar AP, Yun DS, Pollom TS, Belcher AM: Virustemplated iridium oxide-gold hybrid nanowires for electrochromic application. Nanoscale 2012, 4:3405-3409.

38. Lee YJ, Yi H, Kim W-J, Kang K, Yun DS, Strano MS, Ceder G, Belcher AM: Fabricating Genetically Engineered High-Power Lithium-lon Batteries Using Multiple Virus Genes. Science 2009, 324:1051-1055.

39. Kumara MT, Tripp BC, Muralidharan S: Self-Assembly of Metal Nanoparticles and Nanotubes on Bioengineered Flagella Scaffolds. Chem Mater 2007, 19:2056-2064.

40. D'Avignon LC, Hogan BK, Murray CK, Loo FL, Hospenthal DR, Cancio LC, Kim SH, Renz EM, Barillo D, Holcomb JB, et al: Contribution of bacterial and viral infections to attributable mortality in patients with severe burns: An autopsy series. Burns 2010, 36:773-779.

41. Marchetti F, Giglio L, Candusso M, Faraguna D, Assael B: Early antibiotic treatment of pseudomonas aeruginosa colonisation in cystic fibrosis: a critical review of the literature. Eur J Clin Pharmacol 2004, 60:67-74.

42. Lee KK, Sheth HB, Wong WY, Sherburne R, Paranchych W, Hodges RS, Lingwood CA, Krivan H, Irvin RT: The binding of Pseudomonas aeruginosa pili to glycosphingolipids is a tip-associated event involving the C-terminal region of the structural pilin subunit. Mol Microbiol 1994, 11:705-713.

43. Sheth HB, Lee KK, Wong WY, Srivastava G, Hindsgaul O, Hodges RS, Paranchych W, Irvin RT: The pili of Pseudomonas aeruginosa strains PAK and PAO bind specifically to the carbohydrate sequence $\beta G$ alNAC (1-4) $\beta G$ al found in glycosphingolipids asialo-GM1 and asialo-GM2. Mol Microbiol 1994, 11:715-723.

44. Craig L, Pique ME, Tainer JA: Type IV pilus structure and bacterial pathogenicity. Nat Rev Micro 2004, 2:363-378.
45. Lyczak JB, Cannon CL, Pier GB: Establishment of Pseudomonas aeruginosa infection: lessons from a versatile opportunist. Microb Infect 2000, 2:1051-1060.

46. Burrows LL: Weapons of mass retraction. Mol Microbiol 2005, 57:878-888.

47. Burrows LL: Pseudomonas aeruginosa Twitching Motility: Type IV Pili in Action. Annu Rev Microbiol 2012, 66:493-520.

48. Giltner CL, van Schaik EJ, Audette GF, Kao D, Hodges RS, Hassett DJ, Irvin RT: The Pseudomonas aeruginosa type IV pilin receptor binding domain functions as an adhesin for both biotic and abiotic surfaces. Mol Microbiol 2006, 60:813-813.

49. Yu B, Giltner CL, Van Schaik EJ, Bautista DL, Hodges RS, Audette GF, Li DY, Irvin RT: A Novel Biometallic Interface: High Affinity Tip-AssociatedBinding by Pilin-Derived Protein Nanotubes. J Bionanosci 2007, 1:73-83.

50. Mattick JS: Type IV Pili and Twitching Motility. Annu Rev Microbiol 2002, 56:289-314.

51. Skerker JM, Berg HC: Direct observation of extension and retraction of type IV pili. PNAS 2001, 98:6901-6904

52. Conrad Jacinta C, Gibiansky Maxsim L, Jin F, Gordon Vernita D, Motto Dominick A, Mathewson Margie A, Stopka Wiktor G, Zelasko Daria C, Shrout Joshua D, Wong Gerard CL: Flagella and Pili-Mediated NearSurface Single-Cell Motility Mechanisms in P. aeruginosa. Biophys J 2011 100:1608-1616.

53. Jin F, Conrad JC, Gibiansky ML, Wong GCL: Bacteria use type-IV pili to slingshot on surfaces. Proc Natl Acad Sci 2011, 108:12617-12622.

54. Ottow JCG: Ecology, Physiology, and Genetics of Fimbriae and Pili. Annu Rev Microbiol 1975, 29:79-108.

55. van Schaik EJ, Giltner CL, Audette GF, Keizer DW, Bautista DL, Slupsky CM, Sykes BD, Irvin RT: DNA Binding: a Novel Function of Pseudomonas aeruginosa Type IV Pili. J Bacteriol 2005, 187:1455-1464.

56. Dubnau D: DNA Uptake in Bacteria. Annu Rev Microbiol 1999, 53:217-244.

57. Allesen-Holm M, Barken KB, Yang L, Klausen M, Webb JS, Kjelleberg S, Molin S, Givskov M, Tolker-Nielsen T: A characterization of DNA release in Pseudomonas aeruginosa cultures and biofilms. Mol Microbiol 2006, 59:1114-1128.

58. Barken KB, Pamp SJ, Yang L, Gjermansen M, Bertrand JJ, Klausen M, Givskov M, Whitchurch CB, Engel JN, Tolker-Nielsen T: Roles of type IV pili, flagellum-mediated motility and extracellular DNA in the formation of mature multicellular structures in Pseudomonas aeruginosa biofilms. Environ Microbiol 2008, 10:2331-2343.

59. Mikkelsen $\mathrm{H}$, Sivaneson M, Filloux A: Key two-component regulatory systems that control biofilm formation in Pseudomonas aeruginosa. Environ Microbiol 2011, 13:1666-1681.

60. Pelicic V: Type IV pili: e pluribus unum? Mol Microbiol 2008, 68:827-837.

61. Maier B, Potter L, So M, Seifert HS, Sheetz MP: Single pilus motor forces exceed 100 pN. Proc Natl Acad Sci 2002, 99:16012-16017.

62. Craig L, Li J: Type IV pili: paradoxes in form and function. Curr Opin Struct Biol 2008, 18:267-277.

63. Forest KT, Tainer JA: Type-4 pilus-structure: outside to inside and top to bottom - minireview. Gene 1997, 192:165-169.

64. Hazes B, Frost L: Towards a systems biology approach to study type II/IV secretion systems. Biochimica et Biophysica Acta (BBA) - Biomembranes 2008, 1778:1839-1850.

65. Ayers M, Howell PL, Burrows LL: Architecture of the type II secretion and type IV pilus machineries. Future Microbiol 2010, 5:1203-1218.

66. Craig L, Taylor RK, Pique ME, Adair BD, Arvai AS, Singh M, Lloyd SJ, Shin DS, Getzoff ED, Yeager M, et al: Type IV Pilin Structure and Assembly: X-Ray and EM Analyses of Vibrio cholerae Toxin-Coregulated Pilus and Pseudomonas aeruginosa PAK Pilin. Mol Cell 2003, 11:1139-1150.

67. Craig L, Volkmann N, Arvai AS, Pique ME, Yeager M, Egelman Edward H, Tainer JA: Type IV Pilus Structure by Cryo-Electron Microscopy and Crystallography: Implications for Pilus Assembly and Functions. Mol Cell 2006, 23:651-662.

68. Li J, Egelman EH, Craig L: Structure of the Vibrio cholerae Type IVb Pilus and Stability Comparison with the Neisseria gonorrhoeae Type IVa Pilus. J Mol Biol 2012, 418:47-64.

69. Folkhard W, Marvin DA, Watts TH, Paranchych W: Structure of polar pili from Pseudomonas aeruginosa strains K and O. J Mol Biol 1981, 149:79-93.

70. Parge HE, Forest KT, Hickey MJ, Christensen DA, Getzoff ED, Tainer JA: Structure of the fibre-forming protein pilin at $2.6 \mathrm{~A}$ resolution. Nature 1995, 378:32-38 
71. Audette GF, Irvin RT, Hazes B: Crystallographic Analysis of the Pseudomonas aeruginosa Strain K122-4 Monomeric Pilin Reveals a Conserved Receptor-Binding Architecture. Biochemistry 2004, 43:11427-11435.

72. Hazes B, Sastry PA, Hayakawa K, Read RJ, Irvin RT: Crystal structure of Pseudomonas aeruginosa PAK pilin suggests a main-chain-dominated mode of receptor binding. J Mol Biol 2000, 299:1005-1017.

73. Keizer DW, Slupsky CM, Kalisiak M, Campbell AP, Crump MP, Sastry PA Hazes B, Irvin RT, Sykes BD: Structure of a Pilin Monomer from Pseudomonas aeruginosa. J Biol Chem 2001, 276:24186-24193.

74. Kao DJ, Churchill MEA, Irvin RT, Hodges RS: Animal Protection and Structural Studies of a Consensus Sequence Vaccine Targeting the Receptor Binding Domain of the Type IV Pilus of Pseudomonas aeruginosa. J Mol Biol 2007, 374:426-442.

75. Hartung S, Arvai AS, Wood T, Kolappan S, Shin DS, Craig L, Tainer JA: Ultrahigh Resolution and Full-length Pilin Structures with Insights for Filament Assembly, Pathogenic Functions, and Vaccine Potential. J Biol Chem 2011, 286:44254-44265

76. Nguyen Y, Jackson SG, Aidoo F, Junop M, Burrows LL: Structural Characterization of Novel Pseudomonas aeruginosa Type IV Pilins. J Mol Biol 2010, 395:491-503.

77. Bong DT, Clark TD, Granja JR, Ghadiri MR: Self-Assembling Organic Nanotubes. Angew Chem Int Ed 2001, 40:988-1011.

78. Bong DT, Ghadiri MR: Self-Assembling Cyclic Peptide Cylinders as Nuclei for Crystal Engineering. Angew Chem Int Ed 2001, 40:2163-2166.

79. Djalali R, Chen Y-f, Matsui H: Au Nanocrystal Growth on Nanotubes Controlled by Conformations and Charges of Sequenced Peptide Templates. J Am Chem Soc 2003, 125:5873-5879.

80. Zhang S: Fabrication of novel biomaterials through molecular selfassembly. Nat Biotech 2003, 21:1171-1178.

81. Yemini M, Reches M, Gazit E, Rishpon J: Peptide Nanotube-Modified Electrodes for Enzyme-Biosensor Applications. Anal Chem 2005, 77:5155-5159

82. Yemini M, Reches M, Rishpon J, Gazit E: Novel Electrochemical Biosensing Platform Using Self-Assembled Peptide Nanotubes. Nano Lett 2004, 5:183-186.

83. Nam YS, Park H, Magyar AP, Yun DS, Pollom TS, Belcher AM: Virus-templated iridium oxide-gold hybrid nanowires for electrochromic application. Nanoscale 2012, 4:3405-3409.

84. Doig P, Todd T, Sastry PA, Lee KK, Hodges RS, Paranchych W, Irvin RT: Role of pili in adhesion of Pseudomonas aeruginosa to human respiratory epithelial cells. Infect Immun 1988, 56:1641-1646.

85. Schweizer F, Jiao H, Hindsgaul O, Wong WY, Irvin RT: Interaction between the pili of Pseudomonas aeruginosa PAK and its carbohydrate receptor $\beta-D-G a l N A c(1->4)$ B-D-Gal analogs. Can J Microbiol 1998, 44:307-311.

86. Sheth HB, Glasier LM, Ellert NW, Cachia P, Kohn W, Lee KK, Paranchych W, Hodges RS, Irvin RT: Development of an anti-adhesive vaccine for Pseudomonas aeruginosa targeting the $\mathrm{C}$-terminal region of the pilin structural protein. Biomedical peptides, proteins \& nucleic acids: structure, synthesis \& biological activity 1995, 1:141-148.

87. Lombardo S: The Development of Solution and Surface Associated Protein Nanotubes for Applications in Bionanotechnology. M.Sc. thesis, York University, Chemistry Department; 2010.

88. Luft JR, Wolfley JR, Said MI, Nagel RM, Lauricella AM, Smith JL, Thayer MH, Veatch CK, Snell EH, Malkowski MG, DeTitta GT: Efficient optimization of crystallization conditions by manipulation of drop volume ratio and temperature. Protein Sci 2007, 16:715-722.

89. McPherson A: Crystallization of proteins from polyethylene glycol. J Biol Chem 1976, 251:6300-6303.

90. Charles P, Stubbs V, Soto C, Martin B, White B, Taitt C: Reduction of Non-Specific Protein Adsorption Using Poly(ethylene) Glycol (PEG) Modified Polyacrylate Hydrogels In Immunoassays for Staphylococcal Enterotoxin B Detection. Sensors 2009, 9:645-655.

91. Amoozgar Z, Yeo Y: Recent advances in stealth coating of nanoparticle drug delivery systems. WIREs Nanomed Nanobiotechnol 2012, 4:219-233.

92. Tarazona MP, Saiz E: Combination of SEC/MALS experimental procedures and theoretical analysis for studying the solution properties of macromolecules. J Biochem Bioph Methods 2003, 56:95-116.

93. Wyatt PJ: Light scattering and the absolute characterization of macromolecules. Anal Chim Acta 1993, 272:1-40.
94. Audette GF, Irvin RT, Hazes B: Purification, crystallization and preliminary diffraction studies of the Pseudomonas aeruginosa strain K122-4 monomeric pilin. Acta Crystallogr Sect D 2003, 59:1665-1667.

95. Petrov A: Characterization of K122-4-Derived Protein Nanotube Oligomerization and Crystallization of P1 Pilin. M.Sc. thesis, York University, Chemistry Department; 2012.

96. Marvin DA, Nadassay K, Welsh LC, Forest KT: Type-4 bacterial pili: molecular models and their simulated diffraction patterns. Fibre Diffraction Review 2003, 11:87-98.

97. Schneider CA, Rasband WS, Eliceiri KW: NIH Image to ImageJ: 25 years of image analysis. Nat Meth 2012, 9:671-675.

doi:10.1186/1477-3155-11-24

Cite this article as: Petrov et al:: Fibril-mediated oligomerization of pilinderived protein nanotubes. Journal of Nanobiotechnology 2013 11:24.

\section{Submit your next manuscript to BioMed Central and take full advantage of:}

- Convenient online submission

- Thorough peer review

- No space constraints or color figure charges

- Immediate publication on acceptance

- Inclusion in PubMed, CAS, Scopus and Google Scholar

- Research which is freely available for redistribution 